\title{
A DESIGUALDADE DE RENDIMENTOS DO TRABALHO NO PERÍODO PÓS-REAL: O PAPEL DA ESCOLARIDADE E DO DESEMPREGO*
}

Lauro Ramos ${ }^{\S}$

\begin{abstract}
RESUMO
Esse trabalho investiga a evolução da desigualdade de rendimentos do trabalho com base nas PNADs de 1995 a 2005, descrevendo o comportamento das distribuições individual e domiciliar per capita, a influência das mudanças na escolaridade da força de trabalho ocupada sobre a primeira e variações da taxa de desemprego sobre a segunda. Por meio de indicadores baseados no índice T de Theil para a desigualdade e perfil de rendimentos associados à educação, fica claro que essa teve um desempenho importante para a queda da desigualdade de rendimentos individuais na presente década, embora as evidências sejam ambíguas para a década anterior. Quanto ao papel da taxa de desemprego para a desigualdade domiciliar per capita, exercícios de microsimulação, que impõem tanto a taxa de desemprego de 1995 quanto uma taxa nula para todos os anos, indicam uma redução no coeficiente de Gini. Essa redução, todavia, não é muito substantiva, revelando que outros fatores, incluindo aqueles ligados ao aparato institucional que regula o mercado de trabalho brasileiro, têm de ser mais bem examinados.
\end{abstract}

Palavras-chave: Brasil, mercado de trabalho, desigualdade, educação, desemprego.

\begin{abstract}
This study evaluates the evolution of earnings inequality in Brazil based on the 1995 to 2005 national household surveys - PNADs. It describes the behavior of both size and per capita household distributions, assessing the influence of changes related to labor force schooling on the former and of unemployment rate variations on the latter. Synthetic indicators, based on the Theil T index, for schooling inequality and earnings profile show that the role of education was quite important for the fall in inequality along the current decade, although the indications are ambiguous for the previous one. Regarding the unemployment rate, microsimulations exercises that impose either the 1995 rate or zero unemployment lead to a decrease in the Gini coefficient. However, the reduction is not very significant, meaning that the role of unemployment is limited. Taking together, the findings point to the need of a more detailed investigation of other factors, including those related to the labor market institutional framework, in order to develop a better understanding of the recent changes in Brazilian earnings inequality.
\end{abstract}

Key words: Brazil, labor market, inequality, education, unemployment.

JEL Classification: D31, I32, O15.

\footnotetext{
* Parte desse estudo está baseada na contribuição do autor para subsidiar os trabalhos da Comissão Internacional de Alto Nível, coordenada pelo Ipea em 2006 para estudar o comportamento recente da desigualdade de renda no Brasil, e seus desdobramentos.

$\S$ Técnico de pesquisa do Ipea, com apoio do CNPq. E-mail: lramos@ipea.gov.br. Endereço para contato: Av. Pres. Antonio Carlo, 51/14o. andar - Castelo, Rio de Janeiro - RJ - CEP: 20020-010.

Recebido em janeiro de 2007. Aprovado em junho de 2007.
} 


\section{INTRODUÇão}

Desde há muito a sociedade brasileira tem como traço característico a iniqüidade distributiva, apresentando uma das maiores desigualdades na distribuição de renda no mundo inteiro. Essa desigualdade, conforme salientado por Barros et al. (2000), tem conseqüências perversas sobre a incidência de pobreza, realçadas por uma renda per capita insuficiente. Mais preocupante até foi a ausência de indícios de reversão desse quadro no período investigado naquele estudo. A novidade alvissareira, do início da década atual, apresentou uma redução continuada, ainda que relativamente tímida e certamente aquém do ideal, dessa desigualdade, dando seqüência à tendência esboçada no final da década anterior. Conforme destacado em Ipea (2006) que analisa detidamente o período 2001-2004, o patamar observado em 2004 foi, até então, o mais baixo da história das Pesquisas por Amostras de Domicílios (PNADs) do IBGE, segundo os índices de desigualdade mais importantes. Posteriormente, a divulgação da PNAD de 2005 confirmou a continuação da trajetória de queda, mesmo que em ritmo menor.

Este trabalho procura avaliar a evolução da desigualdade de rendimentos do trabalho com base nas PNADs de 1995 a 2005, tendo em conta que: (i) a maior parcela da renda captada pela PNAD é formada pelos rendimentos do trabalho, os quais constituem a principal, e muitas vezes a única, fonte de renda dos indivíduos e das famílias, e (ii) grande parte das variações na desigualdade de renda podem ser atribuídas ao comportamento da desigualdade de rendimentos. ${ }^{2}$ A escolha de 1995 justifica-se por ser esse o primeiro ano de aplicação da PNAD após o Plano Real, que removeu a influência das altas taxas de inflação sobre a dimensão e mensuração da desigualdade, e o de 2005 por ser o último ano coberto por ela disponível no momento. ${ }^{3}$

De modo mais concreto, existem três objetivos maiores: (i) descrever a evolução da desigualdade dos rendimentos do trabalho, em termos de rendimentos individuais de todos os trabalhos e, de forma correlata, de rendimentos domiciliares per capita; (ii) examinar as novas evidências acerca da importância das mudanças da escolaridade da força de trabalho ocupada sobre as variações da primeira delas, e, principalmente, (iii) investigar o impacto das variações da taxa de desemprego sobre a segunda.

A literatura sobre a importância da educação para entender níveis e variações da desigualdade individual é farta, bem como é abundante a investigação empírica sobre essa relação para o caso brasileiro, a começar pelo trabalho de Langoni (1973), que deflagrou o debate sobre a desigualdade de renda no País. Já o impacto distributivo do nível e composição do desemprego é bem menos discutido na literatura e há indicações divergentes. Dedecca et al. (2004), por exemplo, argumentam que variações na taxa de desemprego foram importantes para o comportamento da distribuição familiar per capita entre 1995 e 2002, mas em Ipea (2006) o exercício empírico indica uma importância bastante reduzida. $\mathrm{O}$ fato de essa distribuição, ou a domiciliar per capita, ser mais relevante para fins de avaliação de bem-estar, em conjunto com a relativa escassez de trabalhos sobre a questão, fazem com que o terceiro objetivo seja o ponto principal do trabalho.

1 A renda do trabalho - salários, rendimentos dos trabalhadores por conta própria, bem como o pró-labore dos empregadores - representa mais de 3/4 da renda captada pela PNAD [ver Hoffmann (2006)].

2 Segundo Soares (2006) variações na concentração dos rendimentos do trabalho são responsáveis por $73 \%$ da variação da desigualdade de renda entre 1995 e 2004 e 68\% entre 2001 e 2004. Em Ipea (2006), a queda da desigualdade dos rendimentos do trabalho contribui para metade da redução da desigualdade de renda entre 2001 e 2004. Hoffmann (2006) mostra que, em tempos mais recentes, as transferências de renda se tornaram muito importantes: contribuem em $31 \%$ para a queda entre 2002 e 2004, atingindo $87 \%$ para o Nordeste.

3 Outra vantagem é que o questionário da PNAD não mudou nesse intervalo. A alteração digna de nota é a delimitação de áreas urbanas e rurais entre a pesquisa de 1999 e a de 2001. 
O universo analisado para a distribuição individual consiste de homens e mulheres entre 16 e 70 anos, com renda do trabalho positiva e que residem em áreas urbanas. Foram excluídos da amostra os indivíduos que não possuíam informações (missings) a respeito das características investigadas. Já quando o objeto de análise é a distribuição domiciliar per capita desses rendimentos, todas as pessoas que possuíam um vínculo permanente com domicílios particulares foram consideradas, excluindo, como de praxe, os moradores do domicílio na condição de pensionista, empregados domésticos e seus respectivos parentes.

A próxima seção contém a apresentação da evolução da distribuição, por meio da comparação das curvas de Lorenz e alguns índices de concentração. Na Seção 3, são investigados en passant os principais determinantes do nível da desigualdade ao longo do período. A Seção 4 examina mais detidamente a relação entre mudanças nessa desigualdade e alterações na distribuição de educação na força de trabalho ocupada. A seguir, a Seção 5 avança um pouco na investigação do papel da taxa de desemprego no comportamento da desigualdade por meio de um conjunto de microsimulações. A última seção oferece uma visão geral dos principais resultados. Uma apresentação sucinta de alguns dos dados e estatísticas utilizados é fornecida no final do estudo.

Antes de seguir esses passos, é necessário fazer um breve comentário sobre a questão do salário mínimo, cujo impacto distributivo via mercado de trabalho não será contemplado nesse trabalho. Essa opção não implica desmerecer ou negar sua importância, mas sim uma escolha no sentido de privilegiar outros aspectos. Afinal, como colocado em Soares (2004), "a impossibilidade de comparar dois países idênticos, torna a estimação precisa do impacto distributivo do salário mínimo uma tarefa impossível". Talvez por isso exista tanta polêmica a respeito, desde a época do debate sobre o "efeito farol”. A riqueza de informações coletadas pela PNAD tornou possível estudos empíricos que, em decorrência de hipóteses e abordagens distintas, levam a conclusões diferentes. No que diz respeito à distribuição individual, Neri et al. (2000) mostram que, se respeitado, um aumento do mínimo pode ter impacto razoável sobre a desigualdade individual. Já Corseuil e Carneiro (2001) afirmam que os efeitos sobre desemprego e informalidade são consideráveis, enquanto Ulyssea e Foguel (2006) concluem que o impacto se restringe aos que permanecem ocupados. Em termos da distribuição familiar per capita, Ramos e Reis (1995) encontram efeitos reduzidos para aumentos do mínimo via mercado de trabalho no final da década de 80 . Na mesma toada, Neumark et al. (2006) afirmam que não há evidência para suportar a existência desse efeito sobre a desigualdade de renda, no período 1996-2001, para o Brasil metropolitano. Já Deddeca et al. (2004) argumentam que as fortes elevações do salário mínimo é que impediram que a desigualdade da renda familiar aumentasse entre 1995 e 2002 . Sem dúvida, o potencial de influência do mínimo via mecanismos de transferências de renda deve ter aumentado nos últimos anos, tanto é que, como já citado, essas transferências parecem ter sido responsáveis por parte substantiva da queda observada nos últimos anos. Ainda assim, em Ipea (2006) é externada a preocupação de que talvez esse potencial seja solapado para valores mais altos do salário mínimo. Enfim, a controvérsia é grande e o instrumental analítico ainda não permite avaliações mais precisas. Sem dúvida, é necessário esforço adicional de pesquisa sobre o assunto, mas esse não é o objetivo desse trabalho. Para uma boa revisão da literatura, ver Ulyssea e Foguel (2006) e Corseuil e Servo (2001). 


\section{EVOluÇão DA DESIGUALDADE DE RENDIMENTOS DO TRABALHO NO PERÍODO PÓS-REAL}

Os quatro gráficos que se seguem mostram, em cinza, os ganhos e as perdas porcentuais de cada vigésimo da distribuição individual de rendimentos do trabalho, em termos da variação do total de rendimentos ali concentrada, para os períodos 1995-1999, 1999-2001, 2001-2005 e 19952005. Nos mesmos gráficos, são mostradas, em preto, as diferenças das porcentagens acumuladas do rendimento total até o respectivo vigésimo da distribuição, que nada mais são que as diferenças entre as curvas de Lorenz do final e do início do período. Assim, se o conjunto de barras pretas for sempre positivo, a distribuição do ano final "Lorenz" domina a do ano inicial, o contrário ocorrendo quando os valores forem sempre negativos. ${ }^{4}$ Quando houver valores positivos e negativos, isso é um indicativo de que as curvas de Lorenz se cruzam e, portanto, não há tal dominância para aquele par de anos.

Os Gráficos 1, 3 e 4 indicam a existência de dominância de Lorenz quando se comparam os anos de 1999 com 1995, de 2005 com 2001 e, também, para o período como um todo, quando as diferenças entre as frações acumuladas de rendimentos são mais expressivas (note a mudança da escala vertical no Gráfico 4). O único entre os quatro períodos em que há cruzamento das curvas de Lorenz é aquele entre 1999 e 2001 (Gráfico 2). ${ }^{6}$ A partir desses resultados é possível afirmar que houve uma melhora inequívoca da distribuição individual dos rendimentos do trabalho no final da década anterior e no início da corrente, assim como no decênio em geral, apesar da indefinição na transição de uma década para outra.

Vale notar que os movimentos na distribuição, que levaram à redução da desigualdade, foram diferentes. No final da década de 1990, os ganhos ao longo dos estratos inferiores foram mais homogêneos e abrangentes e se estenderam até o oitavo décimo da distribuição, com o vigésimo superior tendo sido o único estrato a apresentar perdas apreciáveis. No passado mais recente, os ganhos foram mais concentrados e flagrantes nos estratos mais pobres, particularmente no segundo décimo da distribuição, tendo se propagado apenas até o sexto décimo. No período inteiro, o padrão é uma combinação desses dois: os estratos mais pobres obtiveram ganhos mais significativos, também com destaque para o segundo décimo, enquanto os três décimos superiores experimentaram perdas, mais expressivas no último deles.

4 Na verdade trata-se de dominância de segunda ordem, o que não garante dominância de primeira ordem pelo fato de os rendimentos médios reais terem caído durante quase todo o período. Ver Tafner (2006) a respeito.

5 Soares (2006) contém exercício semelhante para a distribuição da renda familiar per capita, enquanto Hoffmann (2006) utiliza a curva de crescimento dos pobres para examinar essa mesma distribuição entre 1997 e 2004. Apesar das diferenças em como retratar os resultados, o intuito comum é o de comparar as curvas de Lorenz.

6 É preciso atentar para o fato de ter havido uma mudança na delimitação de regiões urbanas e rurais nesses anos, o que torna a comparação imperfeita. Como será visto adiante, outros indicadores do mercado de trabalho também apresentam "saltos" entre 1999 e 2001. 
Gráfico 1 - Distribuições de 1995 x 1999

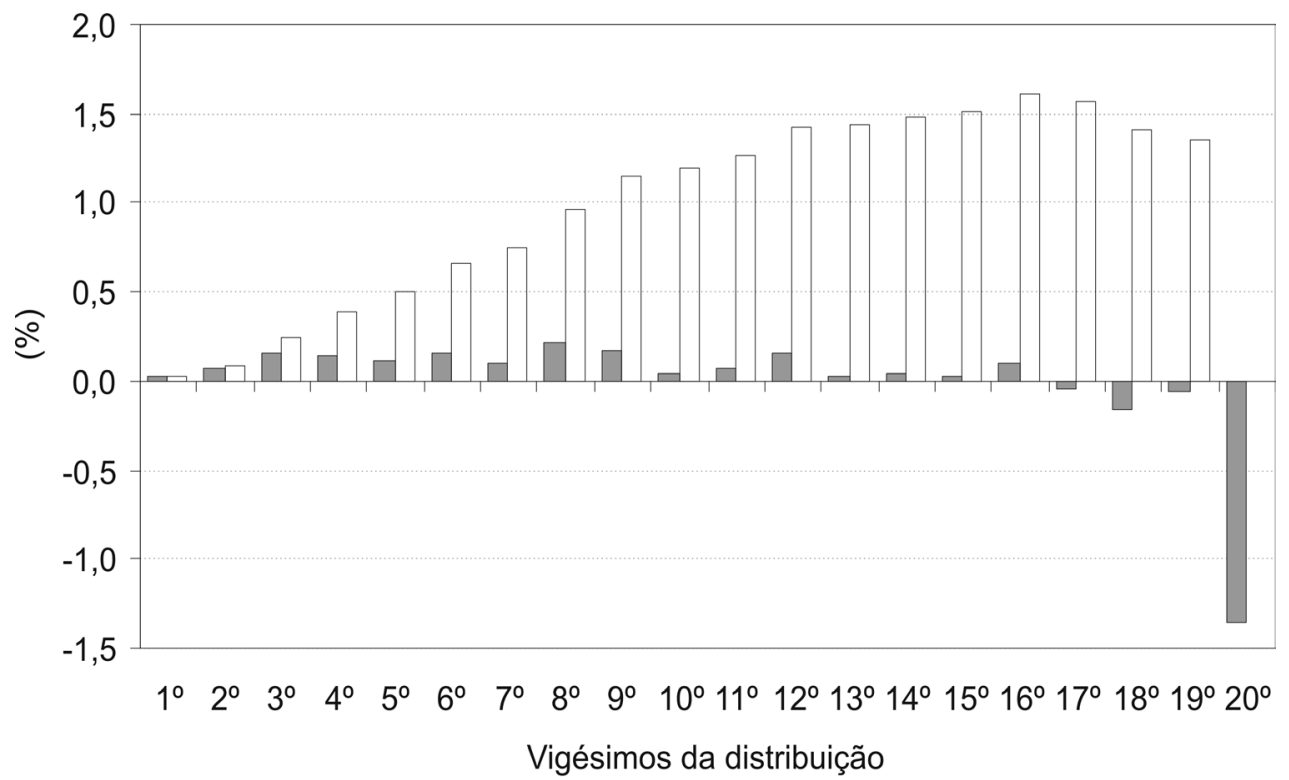

$\square$ Var. renda apropriada $\square$ Var. renda acumulada

Gráfico 2 - Distribuições de 1999 x 2001

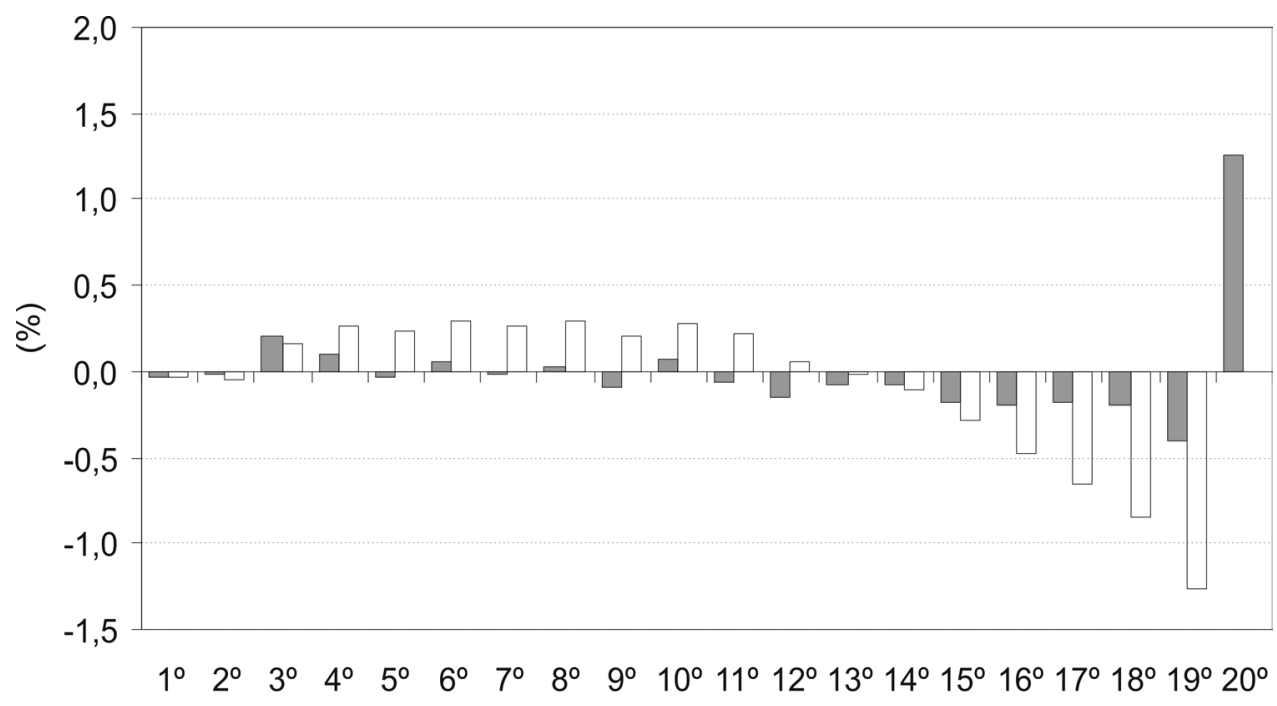

Vigésimos da distribuição

Var. renda apropriada $\square$ Var. renda acumulada 
Gráfico 3 - Distribuições de 2001 x 2005

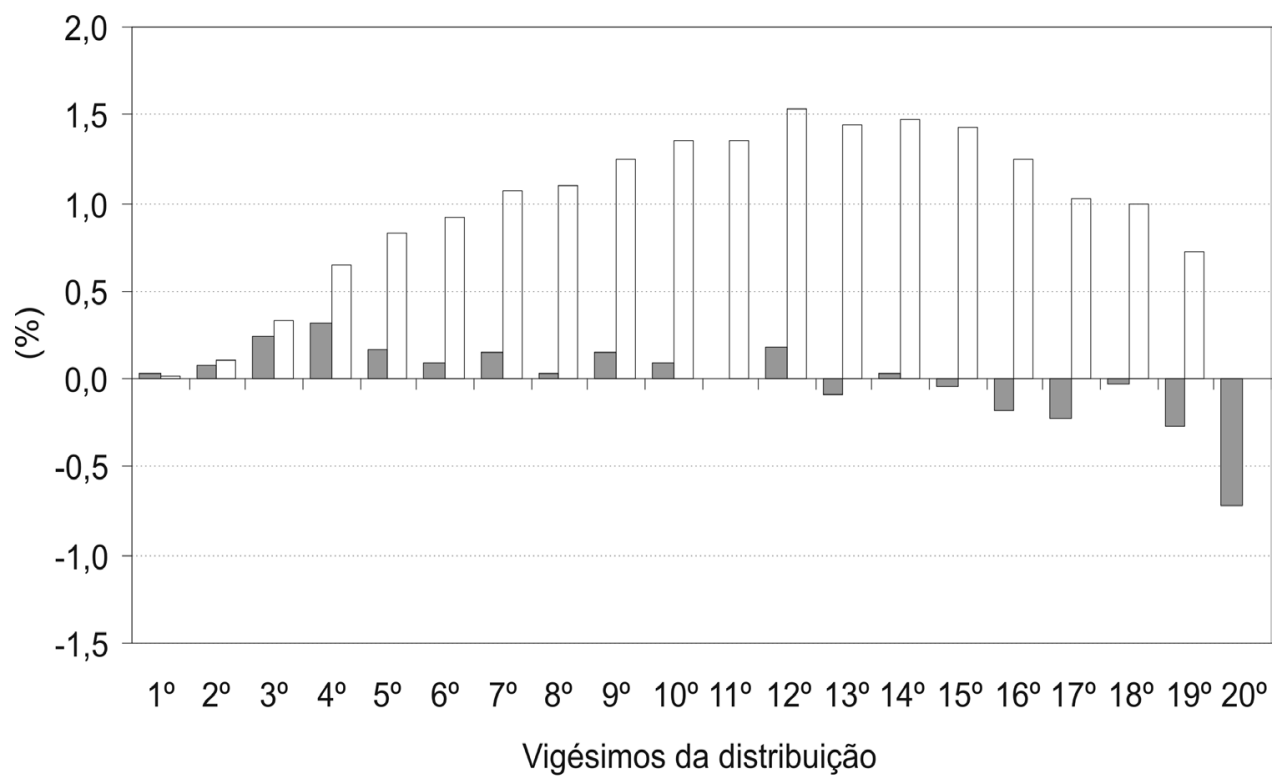

$\checkmark$ Var. renda apropriada $\square$ Var. renda acumulada

\section{Gráfico 4 - Distribuições 1995 x 2005}

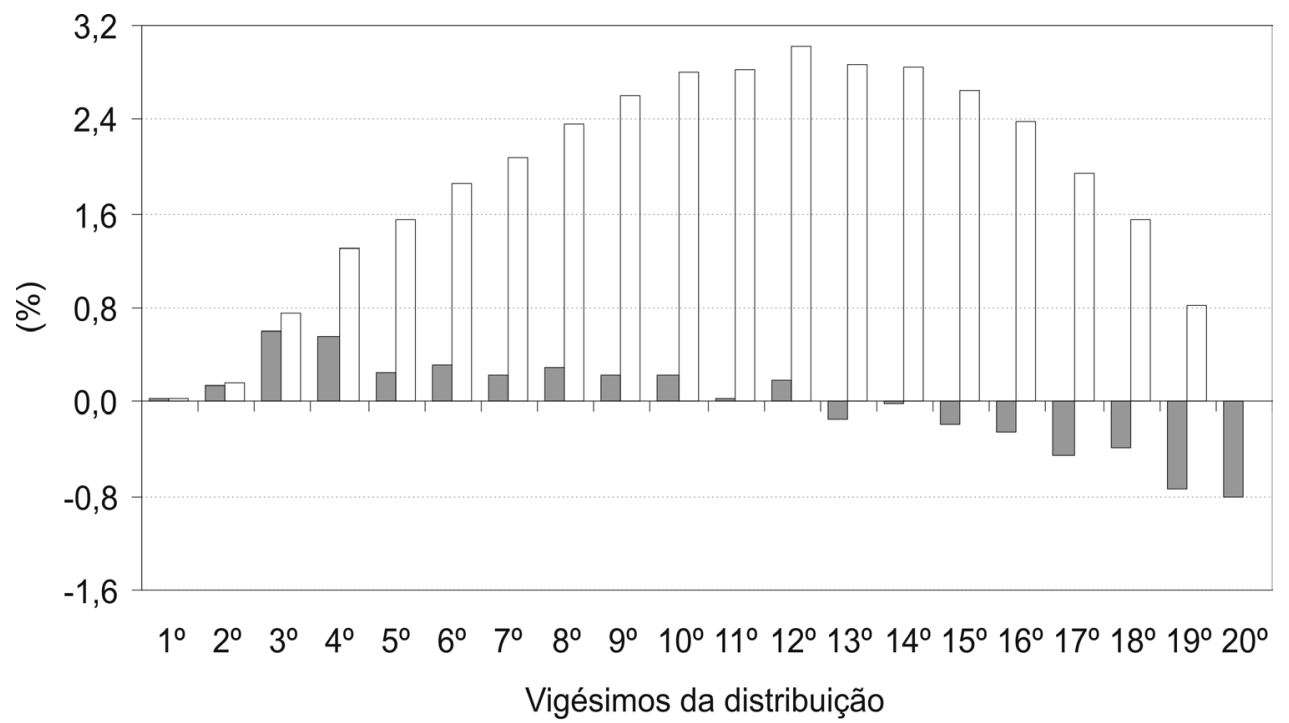

\section{Var. renda apropriada $\square$ Var. renda acumulada}

Como resultado dos movimentos no espectro distributivo, os índices de desigualdade que obedecem à ordenação de Lorenz - uma das propriedades básicas que uma medida de concentração deve possuir para ser considerada aceitável - devem apresentar uma queda no período em geral, 
bem como nos subperíodos do final da década anterior e no início da atual. Os resultados para o coeficiente de Gini, o mais utilizado na literatura, e também para os índices T e L de Theil, são mostrados na Tabela 1.

Como esses três índices satisfazem o critério de Lorenz, os resultados nos períodos 1995-1999, 2001-2005 e 1995-2005 indicam uma queda na desigualdade de rendimentos do trabalho. Já na virada de década, quando as curvas de Lorenz se interceptam, as três medidas indicam uma deterioração na distribuição. ${ }^{7}$ Apesar das diferenças apontadas anteriormente nos movimentos entre os estratos intermediários no final da década passada e no início da atual, vale notar que as variações no coeficiente de Gini são idênticas - 19 pontos de milésimo - nos dois quadriênios e bastante próximas pelo L de Theil - cerca de 40 pontos de milésimo.

Tabela 1 - Evolução da desigualdade de rendimentosa individuais

\begin{tabular}{cccc}
\hline Ano & Theil-T & Theil-L & Gini \\
\hline 1995 & 0,621 & 0,551 & 0,557 \\
1996 & 0,612 & 0,540 & 0,553 \\
1997 & 0,614 & 0,539 & 0,551 \\
1998 & 0,604 & 0,526 & 0,547 \\
1999 & 0,572 & 0,507 & 0,538 \\
2001 & 0,598 & 0,511 & 0,540 \\
2002 & 0,594 & 0,509 & 0,539 \\
2003 & 0,574 & 0,491 & 0,530 \\
2004 & 0,569 & 0,480 & 0,523 \\
2005 & 0,571 & 0,473 & 0,521 \\
\hline
\end{tabular}

Fonte: Pesquisa Nacional por Amostra de Domicílios (PNAD).

Nota: rendimento de todos os trabalhos.

Uma diferença que desperta a atenção entre os dois períodos é que a queda no coeficiente de Gini da distribuição individual não foi repassada à distribuição domiciliar per capita dos rendimentos do trabalho no primeiro deles. De fato, o coeficiente de Gini dessa distribuição fica praticamente estável em torno do patamar de 0,600 entre 1995 e 1999, conforme apresentado no Gráfico 5. Já no período mais recente, os progressos na distribuição individual foram propagados para a distribuição domiciliar per capita, cujo Gini baixou de 0,599 para 0,582 entre 2001 e $2005 .{ }^{9}$

7 Como cada medida de desigualdade traz embutida uma função de bem-estar diferente, não necessariamente os resultados terão que concordar quando não houver dominância de Lorenz. A comparação de 2004 e 2005, cujas curvas de Lorenz se cruzam no último centésimo da distribuição, fornece um bom exemplo dessa situação: enquanto o Gini e o L de Theil indicam uma diminuição da desigualdade, o T de Theil, que responde mais intensamente a mudanças na cauda superior do que eles indica um aumento.

8 Novamente o T de Theil apresenta uma indicação diferente em função da grande elevação em 2001, decorrente dos maiores ganhos do décimo superior (Gráfico 2).

9 Comportamento semelhante é observado para o $\mathrm{T}$ e o $\mathrm{L}$ de Theil. 


\section{Gráfico 5 - Coeficiente de Gini}

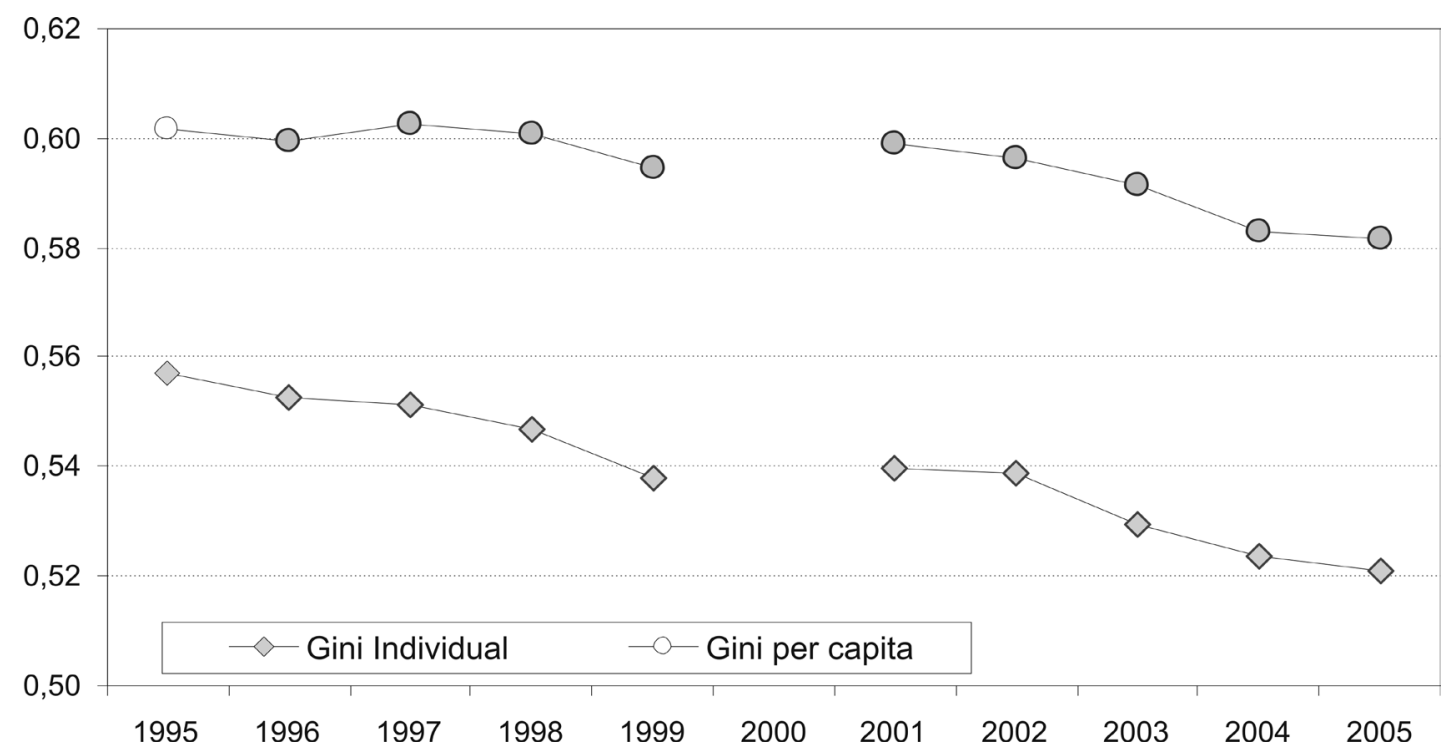

Fonte: Pesquisa Nacional por Amostra de Domicílios (PNAD)

Esse comportamento diferenciado é de natureza complexa, já que depende de fatores diversos, que podem englobar desde mudanças na estrutura familiar até questões associadas ao ambiente econômico e políticas públicas. ${ }^{10}$ Um aspecto que deve ser considerado é que, entre 1995 e 1999, a taxa de desemprego cresceu de forma sensível e continuada, passando de $6,7 \%$ para $10,4 \%$, tendo se estabilizado pouco abaixo do patamar de $10 \%$ entre 2001 e 2005 . Essa constatação pode ser sugestiva de que o aumento do desemprego no final da década passada se deu de modo heterogêneo ${ }^{11}$ e comprometeu o poder aquisitivo das famílias mais atingidas, de forma a anular os progressos distributivos observados nos rendimentos individuais. Nos últimos anos, o efeito do desemprego mais estável pode ter sido neutro, permitindo que esses progressos fossem transmitidos à distribuição domiciliar per capita.

A evidência empírica em Dedecca et al. (2004) mostra que, entre 1995 e 2002, o número médio de desempregados aumentou relativamente mais, e o número de ocupados caiu relativamente mais entre as famílias de baixa renda, o que fornece respaldo para a conjectura acima. A possível associação entre o comportamento do desemprego e a transmissão de diminuição na desigualdade de rendimentos entre indivíduos, para aquela entre domicílios, será investigada com mais detalhes na Seção 5.

10 Hoffmann (2002) trata da distribuição de renda familiar per capita, que inclui, entre outras fontes, os rendimentos provenientes de pensões e aposentadorias, e conclui que a importância destes, que vem crescendo no tempo, é uma das razões para a diferença na evolução das distribuições individual e familiar.

11 Entre 1995 e 1999 a taxa de desemprego aumentou 4 p.p. entre a metade mais pobre dos domicílios e 2 p.p. na outra metade (informação obtida a partir do cômputo dos microdados de cada PNAD). 


\section{FONTES DE DESIGUALDADE DOS RENDIMENTOS INDIVIDUAIS}

Na dinâmica do mercado de trabalho e na sua interação com desigualdades e estratificações sociais preexistentes, há uma série de fatores que podem levar à ocorrência de diferenças de remuneração do trabalho entre os indivíduos e, portanto, afetar o nível da desigualdade de rendimentos, valendo destacar: (i) os diferenciais compensatórios, associados às diferenças entre os postos de trabalho; (ii) a heterogeneidade dos trabalhadores no que se refere ao seu potencial produtivo; (iii) a segmentação, que encerra remunerações distintas a trabalhadores, a princípio, igualmente produtivos, sem base em nenhum critério explícito ou tangível, e (iv) as práticas discriminatórias, que geram diferenças de remuneração entre trabalhadores igualmente produtivos em função de atributivos não-produtivos, como cor e sexo.

Pode-se, então, dizer que o mercado de trabalho funciona tanto como gerador - (iii) e (iv) - quanto como revelador de desigualdades - (i) e (ii). É importante salientar a diferença entre essas situações, pois, além de implicarem graus de indesejabilidade diversos para as desigualdades a elas associadas, elas também demandam políticas de natureza distinta para combatê-las. Nestes termos, uma noção precisa da magnitude e da importância relativa da contribuição dessas fontes, assim como o seu acompanhamento ao longo do tempo, são importantes para traçar um diagnóstico das causas do elevado grau de desigualdade vigente na sociedade brasileira.

A importância relativa dessas fontes de desigualdade será avaliada por intermédio da decomposição do T de Theil, que pertence à classe de medidas de desigualdade aditivamente decomponíveis [Shorrocks (1980)]. O T de Theil, para uma determinada partição da população em G grupos, pode ser escrito da seguinte forma, em que o primeiro termo à direita corresponde à desigualdade entre grupos, ${ }^{12}$ e o segundo à desigualdade intragrupos: ${ }^{13}$

$$
T=\sum_{g} \alpha_{g} \beta_{g} \ln \alpha_{g}+\sum_{g} \alpha_{g} \beta_{g} T_{g}
$$

em que $\beta_{g}, \alpha_{g}$ e $T_{g}$ representam, nessa ordem, a fração da população no g-ésimo grupo, a razão entre a renda média desse grupo e a renda média da população e a desigualdade de renda no interior desse grupo, medida segundo o próprio T de Theil.

A Tabela 2 resume os resultados desse exercício quando aplicado a um conjunto de sete variáveis, que funcionam como proxy para três das fontes de dispersão discutidas no início desta seção. ${ }^{14}$ Os números dessa tabela revelam que, ao longo de todo o período, a heterogeneidade dos trabalhadores, representada aqui por idade e escolaridade, foi a fonte de dispersão mais importante para a explicação da desigualdade de rendimentos, com cerca de $40 \%$ em termos brutos e $30 \%$ em termos marginais. ${ }^{15}$

12 Ou seja, aquela que prevaleceria caso houvesse uma redistribuição de renda no interior de cada grupo que eliminasse as suas desigualdades internas.

13 A parcela da desigualdade total associada às desigualdades internas dos grupos, que se devem a outros fatores/variáveis que não aqueles que nortearam a partição em questão.

14 Os grupos que constituem a desagregação de cada uma das variáveis, bem como as estatísticas calculadas para cada um deles visando a implementação do exercício, são apresentadas no final do trabalho.

15 A contribuição bruta de uma variável para explicar a desigualdade em um determinado instante corresponde à desigualdade entre grupos quando a população é particionada segundo as categorias formadas por aquela variável. De forma análoga, a contribuição marginal corresponderia ao aumento obtido no poder de explicação quando aquela variável é adicionada ao modelo (partição) que contém as demais variáveis consideradas relevantes para a explicação da desigualdade. 
A segmentação - captada no exercício pelas variáveis setor de atividade, posição na ocupação e região geográfica - apresenta uma contribuição bruta razoável, que cai, porém, a cerca da metade na margem (em torno de 1/8), refletindo uma correlação elevada com as outras fontes. Já a discriminação, até onde apreendido por gênero e por cor, tem uma relevância bem menor que as outras duas fontes de dispersão, ficando em torno de $6 \%$ na margem.

Em relação às variáveis associadas à discriminação, cumpre notar que, quando analisados os resultados relativos ao modelo com sete variáveis, a explicação marginal de cor é inferior a sua contribuição bruta, enquanto o oposto ocorre com gênero. Conforme apontado em Ramos e Vieira (2001), esse comportamento distinto se deve, em grande medida, à escolaridade, que é maior entre os brancos e amarelos, ${ }^{16}$ que têm maiores rendimentos, e também maior entre as mulheres, apesar de elas obterem ganhos laborais menores que os homens.

No caso das variáveis relacionadas com a segmentação, o principal destaque é a posição na ocupação, que capta o efeito da informalidade, enquanto setor de atividade e região geográfica apresentam contribuições bem mais modestas. $O$ fato de as contribuições marginais serem bem inferiores às contribuições brutas para a segmentação em geral, e também para a posição na ocupação, sugere que há, por um lado, concentração da informalidade em regiões e setores que remuneram abaixo da média e, por outro, que a escolaridade média é mais baixa entre os trabalhadores informais, bem como em regiões e setores de atividades mais pobres.

Por fim, a fonte de dispersão salarial mais importante - a heterogeneidade dos trabalhadores -, que utiliza idade como proxy para experiência, e escolaridade para qualificação, tem seu poder explicativo amplamente dominado pela variável escolaridade. ${ }^{17}$ A contribuição bruta da escolaridade para a desigualdade em um dado instante é de cerca de $1 / 3$, enquanto sua contribuição marginal gira em torno de $1 / 4$ da desigualdade total. ${ }^{18}$ Ou seja, a importância dessa variável para a explicação do nível de desigualdade de rendimentos do trabalho é equivalente à importância da discriminação e da segmentação tomadas em conjunto, o que justifica uma análise pormenorizada da evolução e da relação das alterações dos retornos à educação e sua distribuição entre a força de trabalho e as variações na desigualdade propriamente dita.

16 Os amarelos são incluídos aqui porque têm rendimentos até superiores que os brancos. Sua contabilização no outro grupo enviesaria a análise e, mais à frente, as estimações econométricas. Por simplicidade, como de resto é comum na literatura, doravante os dois grupos serão denominado simplesmente de "brancos" e "não-brancos".

17 Esse é um resultado comum na literatura, tendo sido encontrado em vários trabalhos. Ramos (1993), para a desigualdade individual de rendimentos, e Ferreira et al. (2006), para a desigualdade da renda domiciliar per capita, são boas referências a respeito.

18 O estudo de Almeida Reis e Barros (1991) encontra uma contribuição de mais de 50\% para a educação no âmbito das metrópoles brasileiras. 
Tabela 2 - Principais determinantes da desigualdade (\%)

\begin{tabular}{|c|c|c|c|c|c|c|c|c|c|}
\hline \multirow{2}{*}{ Fonte } & \multirow{2}{*}{ Variável } & \multicolumn{2}{|c|}{1995} & \multicolumn{2}{|c|}{1999} & \multicolumn{2}{|c|}{2001} & \multicolumn{2}{|c|}{2005} \\
\hline & & $\mathrm{CB}$ & $\mathrm{CM}$ & $\mathrm{CB}$ & $\mathrm{CM}$ & $\mathrm{CB}$ & $\mathrm{CM}$ & $\mathrm{CB}$ & $\mathrm{CM}$ \\
\hline \multicolumn{2}{|c|}{ Heterogeneidade } & 40,3 & 29,2 & 41,6 & 29,7 & 42,2 & 30,8 & 39,8 & 29,4 \\
\hline & Idade & 8,5 & 6,1 & 8,4 & 6,7 & 8,2 & 6,4 & 7,5 & 6,6 \\
\hline & Educação & 33,6 & 23,3 & 34,7 & 23,1 & 35,4 & 24,5 & 33,0 & 23,2 \\
\hline \multicolumn{2}{|c|}{ Discriminação } & 11,6 & 6,4 & 10,8 & 6,1 & 10,0 & 6,0 & 9,6 & 6,3 \\
\hline & Gênero & 4,8 & 5,0 & 3,4 & 4,6 & 3,1 & 4,3 & 3,0 & 4,7 \\
\hline & Cor & 6,6 & 1,8 & 7,1 & 1,9 & 6,6 & 2,2 & 6,3 & 1,9 \\
\hline \multicolumn{2}{|c|}{ Segmentação } & 26,6 & 13,0 & 25,8 & 12,5 & 24,5 & 12,2 & 24,5 & 13,0 \\
\hline & Posição na ocupação & 19,4 & 9,4 & 17,9 & 8,7 & 16,8 & 8,3 & 17,2 & 9,2 \\
\hline & Setor de atividade & 3,9 & 4,7 & 4,5 & 4,9 & 4,2 & 4,6 & 3,4 & 4,9 \\
\hline & Região geográfica & 3,5 & 3,6 & 3,1 & 3,6 & 3,3 & 3,4 & 2,9 & 3,5 \\
\hline
\end{tabular}

Fonte: Pesquisa Nacional por Amostra de Domicílios (PNAD).

CB: contribuição bruta, quando a variável/fonte é considerada isoladamente.

CM: contribuição marginal ou adicional quando a variável/fonte é acrescentada à partição que já contém as demais.

\section{EDUCAÇÃO E A DESIGUALDADE DA DISTRIBUIÇÃO INDIVIDUAL DE RENDIMENTOS}

Dada a importância da heterogeneidade dos trabalhadores para a desigualdade de rendimentos, em particular da sua escolaridade, o objetivo dessa seção é investigar um pouco mais de perto o papel da educação nesse processo nos tempos recentes. Para tanto, é interessante fazer uma breve descrição da interação entre a distribuição de educação e o funcionamento do mercado de trabalho, e suas implicações em termos da desigualdade de rendimentos. Uma visão estilizada destes fatores é ilustrada na Figura 1.

Por um lado, quanto maior a escolaridade média $\left(m^{t}\right)$, maior o rendimento médio $\left(\mu^{t}\right)$. Por outro, quanto maior a desigualdade da distribuição de educação $\left(i^{t}\right)$ e quanto mais inclinado o perfil de rendimentos associados à escolaridade $\left(s^{t}\right)$, resultante da interação entre a distribuição de educação e o modus operandi do mercado, maior será a desigualdade de rendimentos $\left(d^{t}\right)$. Portanto, dada uma desigualdade preexistente, o funcionamento do mercado de trabalho a traduzirá em uma desigualdade de rendimentos de forma mais ou menos intensa, conforme a inclinação do perfil de rendimentos seja maior ou menor. 


\section{Figura 1 - Visão estilizada da interação entre educação e mercado de trabalho}

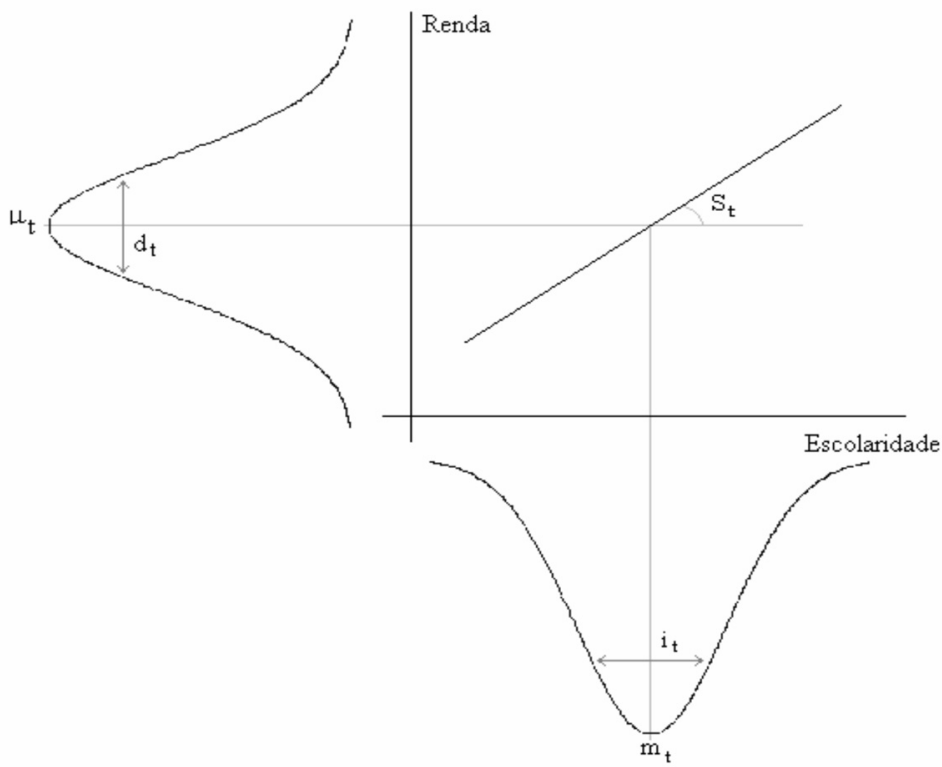

A média ${ }^{19}$ e a desigualdade educacional, assim como a inclinação do perfil de rendimentos, podem ser calculadas segundo a maneira sugerida por Almeida Reis e Barros (1991), qual seja:

$$
\begin{aligned}
& m^{t}=\sum_{i} \alpha_{i}^{t_{0}^{*}} \beta_{i}^{t} \\
& i^{t}=\left(1 / m^{t}\right) \sum_{i} \alpha_{i}^{t_{0}^{*}} \beta_{i}^{t} \ln \left(\alpha_{i}^{t_{0}^{*}}\right)-\ln \left(m^{t}\right) \\
& s^{t}=\left(1 / \sum_{i} \alpha_{i}^{t} \beta_{i}^{t_{0}}\right) \cdot \sum_{i} \alpha_{i}^{t} \beta_{i}^{t_{0}} \log \left(\alpha_{i}^{t}\right)-\log \left(\sum_{i} \alpha_{i}^{t} \beta_{i}^{t_{0}}\right)
\end{aligned}
$$

onde $\beta_{i}^{t}$ é a fração da força de trabalho ocupada que está no grupo com escolaridade $i$ no, período $t, \alpha_{i}^{t}$ é a renda média relativa do grupo $i$ no período $t, t_{0}$ é o período de referência e $\alpha_{i}^{t_{0}}$ são as rendas médias relativas padronizadas para aquele período. ${ }^{20}$

Desse modo a média de escolaridade é dada por uma média ponderada da distribuição segundo os diferentes níveis de escolaridade $\left(\beta_{i}\right)$, sendo os pesos proporcionais à valorização dada pelo mercado em um dado instante (o ano de 2005 foi escolhido como período de referência) em termos de remuneração média de cada grupo educacional. ${ }^{21}$ Já a desigualdade da distribuição de educação

19 Em que pese a média de anos de estudo, seja ela uma candidata natural, e largamente empregada, não necessariamente é o indicador ideal no contexto deste estudo, uma vez que atribui pesos iguais a todos os anos/níveis de educação. A idéia do indicador sintético proposto por Almeida Reis e Barros (1991) é utilizar como proxy para o conteúdo educacional dos diferentes níveis os próprios rendimentos médios relativos.

20 Isto é, de modo que a maior delas, a do grupo com educação superior completa, seja igual a 1. As estatísticas e definição dos cinco grupos de escolaridade considerados encontram-se no final do artigo.

21 Como o ano escolhido como referência foi 2005, os pesos $\alpha_{i}^{t_{0}}(i=1, \ldots 5)=(0,150,0,203,0,229,0,346,1)$. 
e a inclinação do perfil de rendimentos correspondem às desigualdades entre grupos educacionais, caso as rendas relativas ou as frações populacionais de cada grupo, respectivamente, permanecessem inalteradas e iguais às do ano de referência (2005).

A partir das informações sobre os grupos de escolaridade ao final do trabalho, é possível o cálculo desses índices sintéticos, cujos resultados são mostrados na Tabela 3.

Tabela 3 - Índices sintéticos para a relação entre educação e mercado de trabalho

\begin{tabular}{lcccc}
\hline Índice & 1995 & 1999 & 2001 & 2005 \\
\hline$m^{t}$ & 0,289 & 0,303 & 0,310 & 0,334 \\
$i^{t}$ & 0,207 & 0,201 & 0,199 & 0,197 \\
$s^{t}$ & 0,193 & 0,198 & 0,215 & 0,197 \\
\hline
\end{tabular}

A princípio, a evolução ascendente da média, mais flagrante no segundo intervalo, e descendente da desigualdade educacional, mais intensa no primeiro, entre os trabalhadores ocupados, mesmo que em parte devida a uma maior seletividade da própria demanda por trabalho, revelam a existência de condições favoráveis para a redução da desigualdade de rendimentos e a elevação de sua média.

O panorama já não é tão claro, todavia, para o perfil de remuneração dos atributos educacionais, cuja evolução está diretamente ligada ao "efeito compressão" de Knight e Sabot (1983) ou "efeito renda", segundo Ramos (1993); apresenta um ligeiro crescimento entre 1995 e 1999 que, isoladamente, forçaria a desigualdade para cima. A seguir, acontece uma queda mais acentuada desse perfil entre 2001 e 2005, o que, coeteris paribus, acarretaria uma redução na desigualdade de rendimentos do trabalho. ${ }^{22}$ Como o indicador da desigualdade educacional da força de trabalho ocupada, que está relacionado ao "efeito composição" nos trabalhos supracitados, cai ao longo de todo período, ainda que de forma mais intensa no final da década anterior, ele contribui para uma queda de desigualdade nos dois intervalos.

Portanto, as variações associadas à escolaridade da força de trabalho atuam de forma inequívoca no sentido de reduzir a desigualdade individual de rendimentos do trabalho entre 2001 e 2005, na medida em que diminuem tanto os prêmios a ela associados quanto a sua própria desigualdade. Já para o final da década anterior, os dois efeitos - renda ou compressão e composição - atuam em sentidos opostos e o panorama não é tão claro, tomando por base apenas suas indicações qualitativas.

A título de ilustração, ${ }^{23}$ a realização de um exercício de decomposição dinâmica, nos moldes estabelecidos em Ramos (1993), que procura quantificar a intensidade de cada efeito, indicou uma contribuição líquida sempre positiva ${ }^{24}$ das alterações na distribuição da escolaridade da força de trabalho ocupada para a variação na desigualdade de rendimentos, conforme medida pelo T de

22 O salto entre 1999 e 2001 é de difícil explicação, podendo ser decorrência de mudanças na delimitação urbano-rural, já mencionada, ou estar ligado a outros fatores. A ausência de informações comparáveis para o ano de 2000 impossibilita uma avaliação mais embasada.

23 Por questão de espaço não são apresentados os detalhes metodológicos desse procedimento.

24 Isto é, no mesmo sentido da variação da desigualdade de rendimentos (no caso, diminuí-la). 
Theil: cerca de 20\% para o período 1995-1999, 50\% entre 2001-2005 e 25\% para o decênio como um todo.

Sem dúvida, o comportamento dos retornos da educação se deve em grande parte à natureza das mudanças na oferta e demanda por qualificação no âmbito do mercado de trabalho. O caráter não-uniforme da sua evolução indica, todavia, que outros fatores - não apenas os ligados à segmentação e a práticas discriminatórias, mas também aqueles associados ao contexto econômico e de cunho institucional - podem ter desempenhado um papel importante. Uma das possibilidades mais mencionadas é a de que a política do salário mínimo pode ter afetado o processo de formação de rendimentos do trabalho e, portanto, interferido na sua desigualdade, embora, conforme discutido na Introdução, haja grande controvérsia a esse respeito.

Independentemente de qual seja o leque de razões, ponto que deve ser objeto de investigação contínua, o fato é que a queda da desigualdade individual no âmbito do mercado de trabalho contribuiu para a queda da desigualdade da renda total observada nos últimos anos, e o papel da escolaridade, em termos de distribuição e retornos, foi importante para isso, particularmente no período mais recente.

\section{DESEMPREgo E A DESIGUALDADE DA DISTRIBUiÇÃo DOMICILIAR PER CAPITA DOS RENDIMENTOS}

Conforme discutido na Seção 2, o comportamento da concentração dos rendimentos individuais foi diferente da dos rendimentos domiciliares per capita. Essa diferença foi mais acentuada no primeiro período, de 1995 a 1999, quando a queda na desigualdade da distribuição individual praticamente não foi transmitida para a segunda. Já nos anos recentes, o padrão foi mais similar para as duas. Como o final da década passada foi marcado por uma elevação apreciável da taxa de desemprego, enquanto na atual ela manteve-se estável, torna-se interessante investigar se existe alguma ligação entre os dois fenômenos. A indagação que se coloca é se o crescimento assimétrico do desemprego ${ }^{25}$ no período inicial atuou no sentido de neutralizar os progressos distributivos observados nos rendimentos individuais.

$\mathrm{Na}$ verdade, uma resposta cabal a essa questão é difícil de ser obtida, dado o entrelaçamento de dimensões importantes para o resultado final. Por um lado, existe a expansão diferenciada do desemprego por grupos da força de trabalho (educacionais, etários, regionais, ...). Por outro, essa expansão é diferenciada também por estratos de renda. Por fim, a razão maior de ser da dificuldade está no fato de que existe uma relação não trivial entre esses dois movimentos. Assim, a constatação, por exemplo, de que o desemprego subiu mais entre as pessoas que não são chefes de domicílio, que, no plano intuitivo seria menos ruim, que se ele tivesse incidido mais fortemente entre os chefes, não necessariamente implica um impacto menor na desigualdade, pois ela poderia estar concentrada nos estratos inferiores.

Este tipo de dificuldade torna de utilidade duvidosa o recurso à estimação de modelos probabilísticos - do tipo logit, probit, ... - para "correção" dos movimentos na taxa de desemprego, pois embora operacionalmente simples, sua transparência e interpretação ficam prejudicadas pela dificuldade de estabelecer uma clara relação de causalidade. A alternativa utilizada aqui é operacio-

25 Para maiores informações sobre essa evolução ver Tafner (2006). 
nalmente mais trabalhosa, mas bastante transparente, inclusive no que se refere às suas limitações. Será utilizada a técnica de microsimulação para buscar resposta a uma pergunta básica: qual teria sido a evolução da desigualdade domiciliar per capita se a taxa de desemprego não tivesse se alterado, mantendo o nível e estrutura observados em 1995 durante todo o intervalo?

Os estágios envolvidos nesse procedimento são:

- estimação de uma equação de rendimentos - incluindo variáveis tradicionais como idade e educação, além de sexo, cor e região ${ }^{26}$ - para cada um dos anos a partir do conjunto de trabalhadores ocupados; ${ }^{27}$

- seleção aleatória simples de indivíduos desempregados em quantidade que reproduza a taxa de desemprego de $1995 ;^{28}$

- imputação de renda para os selecionados, com base nos valores preditos pela respectiva equação de rendimentos, de acordo com as características de cada um; ${ }^{29}$

- cômputo do índice de desigualdade considerando as rendas imputadas.

Os resultados das simulações para o coeficiente de Gini $^{30}$ são retratados no Gráfico 6, a seguir. Em relação à simulação que impõe para todos os anos a taxa de desemprego observada em 1995, os resultados respaldam a hipótese de que o crescimento dessa variável, até 1999, atuou no sentido de amenizar a propagação dos progressos na distribuição individual para a domiciliar per capita: há um progressivo distanciamento entre a curva original e a simulada nesse período, atingindo seis pontos de milésimo em 1999 (0,595 comparado ao valor simulado de 0,589), com a diferença mantendo-se quase constante na década presente, quando o desemprego permaneceu estável. Para os últimos quatro anos, quando a taxa de desemprego ficou estável, a curva original e a simulada são paralelas, guardando a distância de 1999.

Não obstante, essa diferença não parece expressiva, o que permite conjecturar que, embora tenha havido mudanças na estrutura do desemprego com reflexos sobre a distribuição de rendimentos domiciliares per capita, o efeito delas foi limitado quando comparado ao da heterogeneidade da incidência do desemprego já existente no ano base do exercício.

26 Idade e educação são variáveis "contínuas" (anos de vida e anos completos de estudo, de 0 a 17) e as demais são categóricas, enquanto a variável dependente é o logaritmo dos rendimentos.

27 As estimativas são apresentadas no final do trabalho e, de modo geral, não contêm surpresa alguma.

28 Note que essa implementação é simples porque a taxa de desemprego de 1995 é a mais baixa do período.

29 O uso dos valores preditos pelas equações leva a uma redução da desigualdade simulada por não considerar a dispersão que existiria entre indivíduos aparentemente iguais. Uma alternativa seria considerar uma componente aleatória adicional baseada no erro padrão da regressão. Essa alternativa foi implementada, mas as alterações nos resultados foram ínfimas e, por questão de simplicidade, foi descartada.

30 As simulações foram efetuadas também para os índices de Theil, sem que tenham sido detectadas diferenças significativas em termos qualitativos. Os resultados estão disponíveis mediante solicitação. 


\section{Gráfico 6 - Coeficientes de Gini: original e simulados}

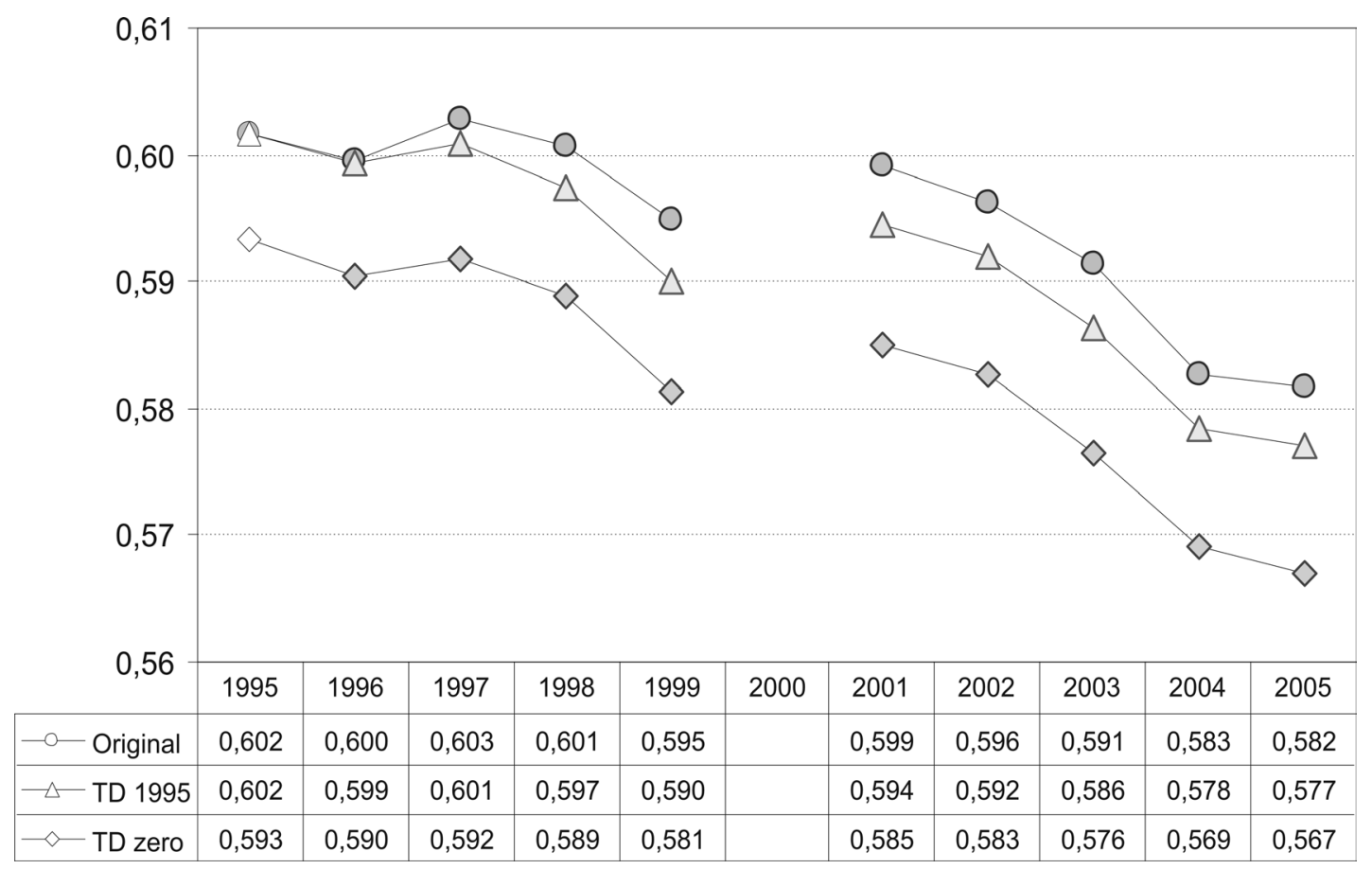

Fonte: Pesquisa Nacional por Amostra de Domicílios (PNAD).

A questão que se coloca então é em que medida a não-neutralidade do desemprego, tanto a original quanto aquela associada às mudanças ao longo do período, afeta a desigualdade de rendimentos domiciliares per capita. Uma maneira simples, mesmo que descolada da realidade, de responder a essa indagação, é considerar uma situação em que não haja desemprego. ${ }^{31} \mathrm{~A}$ simulação com taxa de desemprego nula, também mostrada no gráfico, busca responder essa questão, ainda que de forma aproximada e parcial. Para implementá-la, o segundo e terceiro estágios no procedimento descrito acima são fundidos, e todos os trabalhadores desempregados em determinado instante de tempo são alvo de imputação de renda com base na respectiva equação de rendimentos. ${ }^{32}$

O gráfico deixa claro que, embora o hiato entre os níveis de desemprego nessa simulação seja mais pronunciado, ficando acima de um décimo e atingindo 15 milésimos em 2005, as variações nas diferenças entre os coeficientes de Gini original e os simulados nos dois exercícios são muito parecidas para ambos os períodos: em ambos os casos a distância entre as curvas simuladas e a original aumenta 0,005 no primeiro e fica estável no segundo.

Em suma, as duas simulações indicam que, de fato, a estrutura heterogênea do desemprego afeta a relação entre a distribuição individual de rendimentos do trabalho e a desigualdade da distribuição de rendimentos domiciliares per capita, e sua intensificação entre 1995 e 1999 fez com que sua influência aumentasse. Também é verdade que, à primeira vista, a magnitude desse efeito não parece ser muito expressiva - a Tabela 1 e o Gráfico 5 mostram que a queda no Gini para a

31 Não havendo desemprego, está eliminada, obviamente, qualquer eventual não neutralidade gerada por ele.

32 É preciso ter em mente que a simulação gera um resultado aproximado, pois, mesmo imputando ganhos laborais para todos que estão desocupados na força de trabalho, a oferta de trabalho em cada ano é afetada pelas condições vigentes nesse mercado, entre elas a taxa de desemprego, plausivelmente de forma também diferenciada ao longo dos estratos de renda. 
distribuição individual foi bem superior -, o que sugere suporte limitado para a existência de um papel de grande destaque do desemprego sobre essa desigualdade.

É bem verdade que a dificuldade de interpretar variações em índices de desigualdade não permite que se faça uma afirmação conclusiva a esse respeito. Para fins de ilustração, um meio de ganhar alguma intuição sobre a intensidade das mudanças encontradas para o coeficiente de Gini é por meio da metodologia, ou "métrica”, desenvolvida por Blackburn (1989): em 2005, seria necessário remanejar via transferências das famílias acima da mediana para aquelas abaixo dela o equivalente a $1 \%$ do total de rendimentos do trabalho, para que se obtivesse o coeficiente de Gini simulado com a taxa de desemprego de 1995 , cifra que chegaria a $3 \%$ para o caso da taxa de desemprego nula. Analisado segundo essa ótica, o efeito, ainda que limitado ante a desigualdade total, parece longe de poder ser considerado de importância marginal.

De qualquer maneira, fica claro que um melhor entendimento da relação entre as duas distribuições deve passar, forçosamente, por aspectos ligados à natureza da composição das famílias e domicílios, características do aparato institucional que regula e afeta os resultados do mercado de trabalho e, também, por uma percepção mais precisa de como os programas de transferência de renda afetam a oferta de trabalho. O comportamento da taxa de desemprego afeta essa relação, é verdade, mas contribui de modo limitado para seu entendimento.

\section{RESUMO E COMENTÁRIOS FINAIS}

A constatação que, no período pós-Real, a desigualdade de rendimentos do trabalho diminuiu é inequívoca, seja no plano dos rendimentos individuais, seja no dos rendimentos domiciliares per capita: o coeficiente de Gini passou de 0,567 em 1995, para 0,533 em 2005; para a primeira distribuição, e de 0,602 para 0,582, para a segunda, mesmo comportamento observado segundo os índices de Theil.

Por meio da decomposição do índice T de Theil ficou claro que a heterogeneidade dos trabalhadores é, por larga margem, a principal fonte de dispersão de rendimentos individuais, respondendo por cerca de $40 \%$ da desigualdade total quando considerada isoladamente, e cerca de $30 \%$ quando considerada em conjunto com as variáveis proxy para segmentação e discriminação. Dessas contribuições da heterogeneidade dos trabalhadores, cerca de $4 / 5$ podem ser atribuídos à educação que, em consonância com resultados de outros estudos, contribui para explicar cerca de $1 / 3 \mathrm{em}$ termos brutos, e $1 / 4$ em termos marginais, da desigualdade dos rendimentos individuais em um determinado instante de tempo.

Quanto às variações dessa desigualdade ao longo do tempo, foi demonstrado, por meio de indicadores sintéticos, que a distribuição de escolaridade na força de trabalho, bem como os retornos à educação em si, apresentaram uma evolução favorável para a redução da concentração da distribuição: houve uma redução da desigualdade educacional no final da década passada e uma diminuição do perfil de rendimentos na atual. Assim, não só a educação se mostra importante para "explicar" o nível da desigualdade, como também mudanças associadas a sua distribuição e remuneração são relevantes para a redução desse nível, conforme observado nos anos recentes.

A desigualdade de rendimentos domiciliares per capita, por sua vez, tem um comportamento diferenciado nos dois subintervalos considerados - o quadriênio que fecha a década passada e o que 
inicia a atual. No primeiro deles, de 1995 a 1999, ela é marcada pela estabilidade (notadamente até 1998), sem refletir os progressos na distribuição individual. No segundo, de 2001 a 2005, a queda é flagrante e praticamente no mesmo ritmo observado na individual. Dado o crescimento da taxa de desemprego final dos anos 90, seguido de estabilidade no início da década corrente, a hipótese levantada no trabalho foi de que a não-neutralidade das alterações no desemprego contribuiu para impedir reduções na distribuição domiciliar na década anterior e, estabilizada a taxa, permitiu o repasse dos avanços nos anos mais recentes.

Os exercícios de microsimulação - um deles impondo a taxa de desemprego observada em 1995 para todos os demais, o outro considerando uma situação hipotética de desemprego nulo - revelaram que, de fato, caso a taxa de desemprego não tivesse crescido entre 1995 e 1999, boa parte dos progressos na distribuição entre indivíduos teria sido repassada para a distribuição entre domicílios. Mais ainda, se não houvesse desemprego, a redução na desigualdade domiciliar seria maior, mas as características da queda (diferenças das diferenças) seriam similares às da primeira simulação.

Não obstante sua relevância, o desemprego não altera de forma substantiva a desigualdade domiciliar, o que indica que outros fatores, relacionados à dinâmica dos diferentes mercados e ao aparato institucional, que regula e, portanto, afeta seu funcionamento, têm de ser melhor examinados. Até porque, embora haja algum conhecimento acumulado sobre o efeito de fatores dessa natureza sobre a distribuição individual, como é o caso do salário mínimo, pouco se conhece sobre sua influência na distribuição domiciliar, que é a mais relevante para questões ligadas ao bem-estar.

\section{REFERÊNCIAS BIBLIOGRÁFICAS}

Almeida Reis, J.G.; Barros, R. Wage inequality and the distribution of education: a study of the evolution of the regional differences in inequality in metropolitan Brazil. Journal of Development Economics, n. 36, 1991.

Barros, Ret al. Desigualdade e pobreza no Brasil: retrato de uma estabilidade inaceitável. Revista Brasileira de Ciências Sociais, v.15, n. 42, 2000.

Blackburn, I. Interpreting the magnitude of changes in measures of income inequality. Journal of Econometrics, v. 42, 1989.

Corseuil, C. H.; Servo, L. Salário mínimo e bem-estar social no Brasil: uma resenha da literatura. In: Microeconomia e sociedade no Brasil. Rio de Janeiro: FGV Press, 2001.

.; Carneiro, F. Os Impactos do salário mínimo sobre emprego e salários no Brasil. Ipea, 2001. (Texto para Discussão n. 849).

Dedecca, C. et al. Mudanças na distribuição de renda individual e familiar no Brasil. I Congresso da Associação Latino Americana de População, Caxambu, 2004.

Ferreira, F. et al. Ascensão e queda da desigualdade de renda no Brasil. Econômica, v. 8, n. 1, 2006.

Hoffmann, R. A Distribuição da Renda no Brasil no Período 1992-2001. Economia e Sociedade, v. 11, n. 2, 2002.

. Transferências de renda e a redução da desigualdade no Brasil e cinco regiões entre 1997 e 2004. Econômica, v. 8, n. 1, 2006.

Ipea. Sobre a recente queda da desigualdade de renda no Brasil. Ipea, 2006 (Nota técnica).

Knight, J.; Sabot, R. Education expansion and the Kusnetz effect. American Economic Review, n. 73, 1983. 
Langoni, C. Distribuição da renda e desenvolvimento econômico. Rio de Janeiro: Expressão e Cultura, 1973.

Neri, M. et al. Efeitos informais do salário mínimo e pobreza. Ipea, 2000. (Texto para Discussão n. 724).

Newmark, D. et al. The effects of the minimum wage in Brazil on the distribution of family incomes: 1996-2001. Journal of Development Economics, n. 80, 2006.

Ramos, L. A Distribuição de rendimentos no Brasil: 1976/85. Rio de Janeiro: Ipea, 1993.

.; Reis, J. G. Salário mínimo, distribuição de renda e pobreza no Brasil. Pesquisa e Planejamento Econômico, v. 25, n. 1, 1995.

.; Vieira, M. Desigualdade de rendimentos no Brasil nas décadas de 80 e 90: evolução e principais determinantes. Ipea, 2001. (Texto para Discussão n. 803).

Shorrocks, A. The class of additively decomposable inequality measures. Econometrica, v.52, 1980.

Soares, S. O impacto distributivo do salário mínimo: a distribuição individual dos rendimentos do trabalho. Economia Aplicada, v.8, n.1, 2004.

. Análise do bem-estar e decomposição por fatores da queda na desigualdade entre 1995 e 2004. Econômica, v. 8, n. 1, 2006.

Tafner, P. (Ed.) Brasil: o estado de uma nação - mercado de trabalho, emprego e informalidade. Rio de Janeiro: Ipea, 2006.

Ulyssea, G; Foguel, M. Efeitos do salário mínimo sobre o mercado de trabalho brasileiro. Ipea, 2006. (Texto para Discussão n. 1168). 


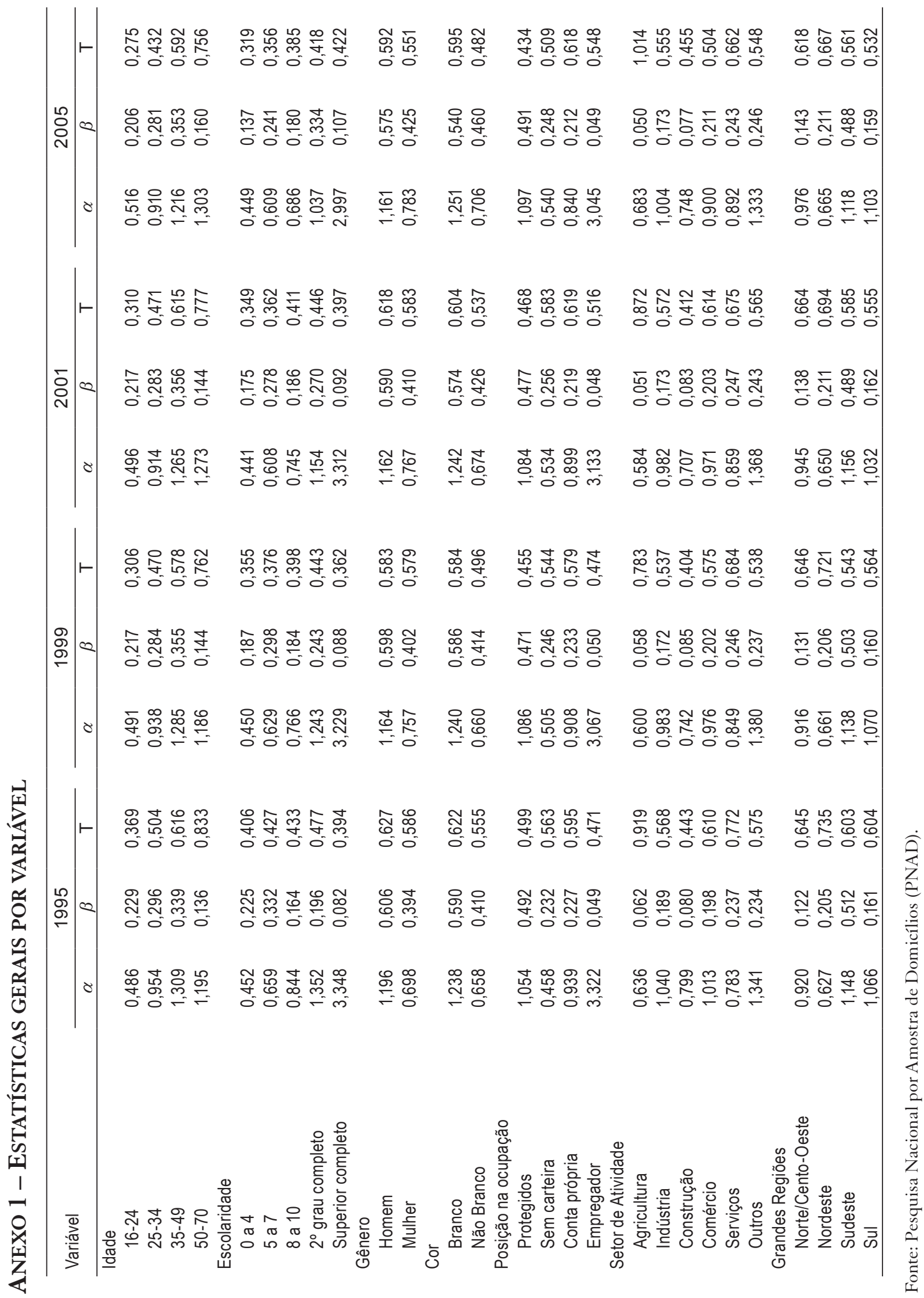




\section{ANEXO 2 - ESTIMATIVAS DOS COEFICIENTES DAS EQUAÇÕES DE RENDIMENTOS}

\begin{tabular}{|c|c|c|c|c|}
\hline Variável & 1995 & 1999 & 2001 & 2005 \\
\hline INTERCEPTO & 2,629 & 2,849 & 2,921 & 3,299 \\
\hline IDADE & 0,088 & 0,088 & 0,089 & 0,085 \\
\hline IDADE $^{2}$ & $-0,001$ & $-0,001$ & $-0,001$ & $-0,001$ \\
\hline EDU1 & 0,143 & 0,148 & 0,135 & 0,105 \\
\hline EDU2 & 0,255 & 0,202 & 0,206 & 0,200 \\
\hline EDU3 & 0,330 & 0,306 & 0,279 & 0,281 \\
\hline EDU4 & 0,496 & 0,443 & 0,439 & 0,408 \\
\hline EDU5 & 0,575 & 0,540 & 0,543 & 0,487 \\
\hline EDU6 & 0,680 & 0,611 & 0,619 & 0,551 \\
\hline EDU7 & 0,729 & 0,654 & 0,644 & 0,600 \\
\hline EDU8 & 0,869 & 0,804 & 0,792 & 0,701 \\
\hline EDU9 & 0,871 & 0,792 & 0,786 & 0,737 \\
\hline EDU10 & 1,007 & 0,924 & 0,909 & 0,804 \\
\hline EDU11 & 1,261 & 1,188 & 1,163 & 1,071 \\
\hline EDU12 & 1,412 & 1,375 & 1,501 & 1,396 \\
\hline EDU13 & 1,598 & 1,553 & 1,528 & 1,461 \\
\hline EDU14 & 1,707 & 1,676 & 1,630 & 1,509 \\
\hline EDU15 & 2,016 & 1,977 & 1,967 & 1,874 \\
\hline EDU16 & 2,235 & 2,218 & 2,217 & 2,110 \\
\hline EDU17 & 2,573 & 2,521 & 2,606 & 2,571 \\
\hline HOMEM & 0,609 & 0,546 & 0,523 & 0,521 \\
\hline BRANCO & 0,168 & 0,161 & 0,160 & 0,137 \\
\hline REG_NO & $-0,110$ & $-0,167$ & $-0,124$ & $-0,087$ \\
\hline REG_NE & $-0,483$ & $-0,472$ & $-0,462$ & $-0,455$ \\
\hline REG_CO & $-0,089$ & $-0,075$ & $-0,031$ & 0,045 \\
\hline REG_SUL & $-0,116$ & $-0,130$ & $-0,104$ & $-0,016^{*}$ \\
\hline R2 & 0,501 & 0,504 & 0,494 & 0,477 \\
\hline $\mathrm{N}$ & 122851 & 129107 & 142184 & 159441 \\
\hline
\end{tabular}

Obs: a variável EDUx equivale ao número (x) de anos completos de estudo.

* O p-valor é 0,003 (para todas as demais p-valor<0,0001). 